\title{
Intelligent Road Inspection with Advanced Machine Learning; Hybrid Prediction Models for Smart Mobility and Transportation Maintenance Systems
}

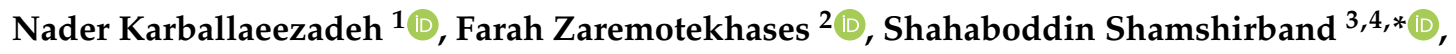 \\ Amir Mosavi ${ }^{5,6,7, *(D)}$, Narjes Nabipour ${ }^{8, *(D)}$, Peter Csiba ${ }^{9}$ and Annamária R. Várkonyi-Kóczy ${ }^{9,10, *}$ \\ 1 Faculty of Civil Engineering, Shahrood University of Technology, Shahrood 3619995161, Iran; \\ n.karballaeezadeh@gmail.com \\ 2 Department of Construction Management, Louisiana State University, Baton Rouge, LA 70803, USA; \\ Fzarem1@1su.edu \\ 3 Department for Management of Science and Technology Development, Ton Duc Thang University, \\ Ho Chi Minh City, Vietnam \\ 4 Faculty of Information Technology, Ton Duc Thang University, Ho Chi Minh City, Vietnam \\ 5 Thuringian Institute of Sustainability and Climate Protection, 07743 Jena, Germany \\ 6 Institute of Structural Mechanics, Bauhaus University Weimar, D-99423 Weimar, Germany \\ 7 School of the Built Environment, Oxford Brookes University, Oxford OX30BP, UK \\ 8 Institute of Research and Development, Duy Tan University, Da Nang 550000, Vietnam \\ 9 Department of Mathematics and Informatics, J. Selye University, 94501 Komarno, Slovakia; csibap@ujs.sk \\ 10 Institute of Automation, Obuda University, 1034 Budapest, Hungary \\ * Correspondence: shahaboddin.shamshirband@tdtu.edu.vn (S.S.); amir.mosavi@uni-weimar.de (A.M.); \\ narjesnabipour@duytan.edu.vn (N.N.); koczya@ujs.sk (A.R.V.-K.)
}

Received: 18 January 2020; Accepted: 27 March 2020; Published: 4 April 2020

\begin{abstract}
Prediction models in mobility and transportation maintenance systems have been dramatically improved by using machine learning methods. This paper proposes novel machine learning models for an intelligent road inspection. The traditional road inspection systems based on the pavement condition index (PCI) are often associated with the critical safety, energy and cost issues. Alternatively, the proposed models utilize surface deflection data from falling weight deflectometer (FWD) tests to predict the PCI. Machine learning methods are the single multi-layer perceptron (MLP) and radial basis function (RBF) neural networks as well as their hybrids, i.e., Levenberg-Marquardt (MLP-LM), scaled conjugate gradient (MLP-SCG), imperialist competitive (RBF-ICA), and genetic algorithms (RBF-GA). Furthermore, the committee machine intelligent systems (CMIS) method was adopted to combine the results and improve the accuracy of the modeling. The results of the analysis have been verified through using four criteria of average percent relative error (APRE), average absolute percent relative error (AAPRE), root mean square error (RMSE) and standard error (SE). The CMIS model outperforms other models with the promising results of APRE $=2.3303$, $\mathrm{AAPRE}=11.6768, \mathrm{RMSE}=12.0056$ and $\mathrm{SD}=0.0210$.
\end{abstract}

Keywords: transportation; mobility; prediction model; machine learning; pavement management; pavement condition index; highway; structural health monitoring; falling weight deflectometer; multilayer perceptron; radial basis function; artificial neural network; intelligent machine system committee

\section{Introduction}

In road transportation, pavement plays a vital role as the part of the road that is in direct contact with vehicles. The Maintenance, Rehabilitation and Reconstruction (MR\&R) program of the pavement 
network is a multidimensional decision-making process that takes into account several considerations. Highway agencies generally focus on two issues: Maximizing the efficiency of the pavement network or minimizing agency costs [1]. Both of these issues require the estimation of operating conditions of the pavement network to set up pavement management and maintenance plans.

Inspection of pavement surface distress is essential before setting up a maintenance plan to determine the pavement operating conditions. Pavement network maintenance operations are arranged based on the state of such distresses [2]. Table 1 shows an instance of pavement network maintenance operations based on pavement status.

Table 1. Maintenance program in roads [2].

\begin{tabular}{ccc}
\hline Damage (\%) & Condition & Maintenance Program \\
\hline$<6$ & Good & Routine Maintenance \\
$6-11$ & Moderate & Minor Rehabilitation \\
$11-15$ & Light Damage & Major Rehabilitation \\
$>\mathbf{1 5}$ & Heavy Damage & Reconstruction \\
\hline
\end{tabular}

Inspection and evaluation of pavement conditions is the most important factor for the effective and economical maintenance of the pavement network that can lead to the promotion of service life [3]. The condition of an in-service pavement is assessible in two categories, including functional and structural. Both functional and structural conditions play an important role in pavement management at the network level [4]. In most Pavement Management Systems (PMSs), non-structural indices are used as pavement indicators to select treatments [3,5] while ignoring the structural conditions of pavement [6]. It has recently been proven that there is a statistical relationship between functional and structural conditions [7].

A very common non-structural index in the PMSs is the pavement condition index (PCI), which was developed by the US Army Corps of Engineers in 1982. PCI is an indicator of surface functional condition and structural integrity [8]. After visual inspection of the pavement network, pavement engineers calculate PCI based on distress type, severity and quantity. This index varies from zero for a virtually unusable pavement to 100 for a perfect pavement [9]. On the other hand, the assessment of structural conditions is generally performed by non-destructive tests such as falling weight deflectometer (FWD) [10-13]. In the FWD test, an impulsive load applies to the pavement surface for 25-30 ms and the surface deflections are recorded by seven (or more) sensors. The sensors' measurements are analyzed by back-calculation software, such as ELMOD and MODULUS, and useful information, including overlay thickness, layers modulus and remaining life, is determined [14-16].

Nowadays, $\mathrm{PCI}$ calculation in many organizations is done using automated distress identification from digital images, but some organizations are still using traditional methods for PCI determination. The traditional process of calculating PCI in a pavement segment involves the visual inspection of pavement. This type of inspection has always raised safety concerns among engineers. When an inspector is recording surface pavement distresses, the possibility of crashing into road traffic is relatively high. Another drawback of the PCI calculation process is concerned with potential human error in identifying and recording pavement distress. Human error can affect the accuracy of the calculated PCI. In this paper, the authors propose a novel method for estimating PCI in flexible pavements. In the proposed method, the PCI of a pavement segment can be calculated based on the surface deflections recorded in the FWD testing. Another major incentive of the authors was the inadequacy of studies on the link between PCI and pavement surface deflection in the FWD testing.

To implement the proposed method, the authors selected 236 pavement segments from Tehran-Qom freeway in Iran. First, PCI was calculated by inspecting all segments and recording surface distresses data. Then, all the segments were subjected to FWD testing and the average deflection of each segment 
was determined. After completing the database, the analysis stage was carried out with the help of machine learning (ML) techniques. ML techniques are a sub-category of computational intelligence. These techniques are chiefly applied for function approximation, classification, pattern recognition, etc. [17]. ML algorithms have recently gained popularity in PMS studies [18-29]. In this paper, multi-layer perceptron (MLP) and radial basis function (RBF) neural networks were used for data analysis. The optimization of MLP neural network was conducted by Levenberg-Marquardt (LM) and scaled conjugate gradient (SCG) algorithms and the RBF neural network was optimized by the genetic algorithm (GA) and imperialist competitive algorithm (ICA). Therefore, the analytical methods used in this paper are MLP-LM, MLP-SCG, RBF-GA and RBF-ICA. Finally, to obtain more accurate results, all four methods were merged with committee machine intelligent systems (CMIS) in a single model. The results of these five methods were assessed using average percent relative error (APRE), average absolute percent relative error (AAPRE), root mean square error (RMSE) and standard error (SE) criteria to determine the accuracy of each method.

The proposed method enhances the safety of the PCI determination process by eliminating the field inspection of the pavement. Also, by removing the human factor from the inspection process, the potential human error is eradicated, and the results are boosted. Furthermore, the use of FWD test results to estimate PCI provides to the overlapping and cost-effectiveness of the pavement network maintenance activities.

This paper is organized as follows. Section 1 presents the introduction and contribution of the paper. Section 2 reviews relevant studies in the literature. In Section 3, the research methodology is presented. This section also includes an introduction to PCI and its calculation method, the FWD test, the freeway understudy and data analysis methods. At the end of this section, the validation criteria of the results are presented. Section 4 discusses the results and conclusions are drawn in Section 5.

\section{Literature Review}

The manual and visual pavement distress analysis method is the simplest method for pavement evaluation. However, this method is time-consuming, subjective, dangerous, tedious, labor-intensive, leads to inconsistencies in distress detail, has a high degree of variability and is very costly $[30,31]$. Automatic and semi-automatic systems can overcome these problems. In recent years, automatic and semi-automatic systems such as image-based approaches [32-36], ground penetrating radar (GPR) [37], fiber optic sensors [38] and laser systems (LS) [37,39-41] have been used by pavement researchers and engineers. Despite the advantages of automatic and semi-automatic methods, many government and research centers in Iran are unable to use these types of equipment due to budgetary constraints, and they evaluate the pavement with the same manual and visual inspections.

The pavement inspection on each road is based on different indices. One of these indices is PCI. In addition to the conventional method of determining PCI, several other attempts have been made to predict this index. PCI prediction methods can be broadly divided into three categories:

1. PCI prediction methods based on other pavement quality indices.

2. $\quad$ PCI prediction methods based on pavement age.

3. PCI prediction methods based on pavement surface deflection.

The first category represents the most frequent method used by other researchers. In this category, PCI of flexible pavement is determined based on other indices that manifest pavement quality. Surface pavement distresses have a direct relationship with other indicators of pavement distress, including roughness and driving quality. Table 2 depicts a number of methods in this category. 
Table 2. Pavement condition index (PCI) prediction methods based on other pavement quality indices.

\begin{tabular}{|c|c|c|}
\hline Model & Equation & Description \\
\hline Park et al. [42] & $\log (\mathrm{PCI})=2-0.436 \log (\mathrm{IRI})$ & IRI: International roughness index. \\
\hline Dewan and Smith [43] & $\mathrm{PCI}=153-\frac{\mathrm{IRI}}{0.0171}$ & $\begin{array}{l}\text { IRI: International roughness index. } \\
\text { IRI: International roughness index, }\end{array}$ \\
\hline Arhin et al. [44] & $\mathrm{PCI}=(\mathrm{A} \times \mathrm{IRI})+\mathrm{K}+\varepsilon$ & $\begin{array}{l}\text { A and K: Regression coefficients, } \\
\varepsilon \text { : Error }\end{array}$ \\
\hline $\begin{array}{l}\text { Korea institute of } \\
\text { construction } \\
\text { technology [45] }\end{array}$ & $\mathrm{NHPCI}=\left(\left(0.004 \mathrm{x}_{\mathrm{RD}}\right)+\left(0.003 \mathrm{x}_{\mathrm{CR}}\right)+\left(0.0183 \mathrm{x}_{\mathrm{IRI}}\right)+0.33\right)^{-2}$ & $\begin{array}{c}\text { NHPCI: National highway } \\
\text { pavement condition index, } \\
\mathrm{x}_{\mathrm{RD}}: \text { Ruth depth }(\mathrm{mm}), \\
\mathrm{x}_{\mathrm{CR}} \text { : Crack ration }(\%), \\
\mathrm{x}_{\mathrm{IRI}} \text { : International roughness index }(\mathrm{m} / \mathrm{km}) \text {. }\end{array}$ \\
\hline $\begin{array}{l}\text { Korea expressway } \\
\text { corporation research } \\
\text { institute [45] }\end{array}$ & $\mathrm{HPCI}=5-0.75 \mathrm{RD}^{1.2}-0.54 \mathrm{IRI} \mathrm{I}^{0.8}-0.9 \log (1+\mathrm{SD})$ & $\begin{array}{l}\text { HPCI: Highway pavement condition index, } \\
\text { RD: Ruth depth }(\mathrm{mm}), \\
\text { IRI: International roughness index }(\mathrm{m} / \mathrm{km}), \\
\text { SD: Surface distress (crack quantity } \\
\text { converted to area) }\left(\mathrm{m}^{2}\right) .\end{array}$ \\
\hline Ningyuan et al. [46] & $\mathrm{PCI}=\mathrm{DMI} \times \mathrm{C}_{\mathrm{i}} \times \sqrt{0.1 \times \mathrm{RCI}} \times 10$ & $\begin{array}{l}\text { DMI: Distress manifestation index, } \\
\mathrm{C}_{\mathrm{i}} \text { : Calibration coefficient for } \\
\text { pavement type, } \\
\text { RCI: Riding comfort index. }\end{array}$ \\
\hline Khattak et al. [47] & $\begin{array}{l}\text { 1. Avg (RNDM, ALCR, PTCH, RUFF, RUT)- } \\
\text { 0.85STD(RNDM, ALCR, PTCH, RUFF, RUT) } \\
\text { 2.Min (RNDM, ALCR, PTCH, RUFF, RUT) }\end{array}$ & $\begin{array}{l}\text { RNDM: Random cracking index, } \\
\text { ALCR: Alligator cracking index, } \\
\text { PTCH: Patch index, } \\
\text { RUFF: Roughness index, } \\
\text { RUT: Rutting index. }\end{array}$ \\
\hline
\end{tabular}

In the second category of PCI prediction methods, researchers focus on pavement age as a major prediction factor. The pavement age is directly linked to pavement distresses so that different types of distress are more likely to appear in an old pavement segment. Table 3 reveals examples of methods in this category.

Table 3. PCI prediction methods based on pavement age.

\begin{tabular}{|c|c|c|}
\hline Model & Equation & Description \\
\hline $\begin{array}{l}\text { South Dakota } \\
\text { Department of } \\
\text { Transportation [48] }\end{array}$ & $\mathrm{PCI}=\mathrm{a}+\left(\mathrm{b} \times \mathrm{age}^{\mathrm{c}}\right)$ & $\begin{array}{c}\text { a: Maximum value of PCI, } \\
\text { Age: Age of pavement (year), } \\
\text { b: Slop coefficient of performance curve, } \\
\text { c: Power coefficient for performance curve. }\end{array}$ \\
\hline $\begin{array}{l}\text { Oklahoma airfield } \\
\text { pavement } \\
\text { management } \\
\text { system [49] }\end{array}$ & $P C I=a_{0}+a_{1} x+a_{2} x^{2}+\cdots+a_{n} x^{n}$ & $\begin{array}{c}\mathrm{a}_{\mathrm{i}} \text { : Polynomial parameters, } \\
\text { x: Pavement age, } \\
\text { n: Polynomial order. }\end{array}$ \\
\hline Michles [50] & $\begin{array}{c}\mathrm{PCI}= \\
71.09+27.42(\text { Treatment type })-4.07(\text { Age })\end{array}$ & $\begin{array}{c}\text { Treatment type: } 0 \text { for microsurfacing and } \\
1 \text { for thin overlay, } \\
\text { Age: Pavement age (year). }\end{array}$ \\
\hline
\end{tabular}

The third category of PCI prediction methods involves the pavement surface deflections in the FWD test. FWD is a device used to evaluate the structural capacity of pavements. The appearance of different types of surface distress on pavements and their expansion reflects the deterioration of the structural capacity of pavements. Given the above points, there is a mutual relationship between the FWD testing process and surface distresses of pavement. The paucity of research in this area was one of the reasons prompting the authors to investigate the relationship between pavement deflection data and the PCI index. One of the few studies that fall into this category of PCI prediction methods is the research undertaken by $\mathrm{O}^{\prime}$ Brien et al. They developed a model for predicting PCI, which in addition to deflections of surface pavement, drew on traffic data, pavement age and type of pavement [51]. Equation (1) shows the model proposed by O'Brien et al.: 


$$
\begin{aligned}
\mathrm{PCI}= & 96.6-\left[\left(0.000572 \times \mathrm{AGE}^{2} \times \mathrm{LPMTOT} \times \mathrm{DIFF} \times \mathrm{AREA}\right)\right. \\
& +\left(0.3062 \times \mathrm{AGE}^{\frac{1}{4}} \times \mathrm{AGESOL}^{2} \times \mathrm{DIFF}^{2}\right) \\
& \left.+\left(0.00156 \times \mathrm{AGE}^{\frac{1}{2}} \times \mathrm{AGETOT} \times \mathrm{LPMTOT} \times \mathrm{DIFF} \times \mathrm{AREA}\right)\right]
\end{aligned}
$$

where, AGE: age of pavement since last overlay (year), LPMTOT: log of weighted traffic total (veh/day), and DIFF: normalized deflection basin slope:

$$
\mathrm{DIFF}=\frac{\mathrm{D}_{0}-\mathrm{D}_{12}}{\mathrm{D}_{0}}
$$

where, $\mathrm{D}_{\mathrm{i}}$ : pavement surface deflection at $\mathrm{i}$ inches from center of loading plate in the FWD test, and AREA: area of FWD deflection basin at the high load level (in. ${ }^{2} / 10^{3}$ ):

$$
\operatorname{AREA}=12\left(D_{0}+D_{12}\right)
$$

where, AGESOL: age of pavement to last overlay (year), and AGETOT: total age of pavement (year).

The data used by O'Brien et al. were obtained from Virginia in the United States. In this study, the pavement surface deflections data were collected using Dynatest 8000 FWD. Statistically, Equation (1) is moderately accurate, for a correlation coefficient $\left(R^{2}\right)$ and a standard error $(\sigma)$ of 0.586 and 6.88 were obtained, respectively [51].

ML can combine statistics and computer sciences to produce sophisticated models that are effective in predicting and deciding on pavement engineering [52]. ML can help researchers to optimize pavement management programs. If these techniques are well designed and implemented, they will yield better results from empirical and statistical models. In recent years, many researchers have used machine learning techniques in pavement engineering such as Artificial Neural Network (ANN) [53-61], Support Vector Machine (SVM) [16,26,52,58,60,62,63], Random Forest (RF) [60,64], Deep-Learning (DL) network [65], Data Mining (DM) [54], Radial Basis Function (RBF) neural network [58], adaptive neuro-fuzzy inference system [66], Group Method of Data Handling (GMDH) [66], Gene Expression Programming (GEP) [61,62,67], Scikit-Learn [68], hybrid Artificial Neural Network/Simulated Annealing (ANN/SA) [67], Naïve Bayes [52], etc.

Safety has always been a key factor in transportation engineering. As such, one major strength of the method proposed in this paper is that it eliminates the need for field inspection of pavement surface distresses, which significantly promotes inspection safety. On the other hand, whenever the human factor is involved in scientific processes, the possibility of error induced by inaccuracy and distraction cannot be ruled out. Thus, the accuracy of the PCI estimation process could be improved by eliminating the human factor. Another strength of this study lies in its application of FWD. Due to its very accurate simulation of traffic load, FWD is a valid test endorsed by all transportation agencies and is extensively used in many parts of the world for structural evaluation of pavements. Therefore, the simultaneous use of FWD testing for structural evaluation of the pavement network and PCI estimation contributes to the overlapping of maintenance activities and diminishes the consumption budget. The last achievement of this is concerned with its role in filling the research gap in this area, which could lay the ground for future research in this field.

\section{Materials and Methods}

\subsection{Pavement Condition Index (PCI)}

One of the most common indices used to evaluate flexible pavement is PCI. Introduced by the US Army Corps of Engineers, this index is based on visual inspection of pavement [62,69]. The PCI value is a number from 100 to zero, with 100 representing the best pavement conditions and zero indicating the worst pavement conditions. To calculate PCI in a pavement segment, initially, number 100 is 
assigned to that segment. Then, based on the type, extent and severity of the pavement distresses, a deduct value (DV) is subtracted until PCI is finally obtained [70]. Table 4 shows the relationship between the pavement status and the value of PCI.

Table 4. Rating scale of PCI [71].

\begin{tabular}{cccccccc}
\hline PCI & $0-10$ & $10-25$ & $25-40$ & $40-55$ & $55-70$ & $70-85$ & $85-100$ \\
\hline Condition & Failed & Serious & Very poor & Poor & Fair & Satisfactory & Good \\
\hline
\end{tabular}

The process of PCI calculation in flexible pavements is summarized as follows [71,72]:

1. Determine the type, extent and severity of pavement distresses.

2. Determine DV for each distress based on its corresponding curve [72].

3. Reduce the number of DVs to the maximum number allowed by Equation (4):

$$
\mathrm{m}_{\mathrm{i}}=1+\frac{(100-\mathrm{HDV}) \times 9}{98}
$$

where, $\mathrm{m}_{\mathrm{i}}$ : maximum allowable number of deduct values, and HDV: greatest individual deduct value.

1. Determine the number of DVs greater than 2 (q).

2. Determine total deduct value (TDV), which is the sum of DVs.

3. Determine corrected deduct value (CDV) based on correction curves using q and TDV [72].

4. Decrease the smallest DVs larger than 2 to 2 .

5. Repeat steps 4 to 7 until q reaches 1.

6. Determine the maximum CDV and calculate the PCI using Equation (5):

$$
\mathrm{PCI}=100-\mathrm{CDV}_{\max }
$$

\subsection{Falling Weight Deflectometer (FWD)}

Structural evaluation of the pavement network is one of the requirements of pavement management systems and FWD is the most common test for structural evaluation of pavement [73]. This test is widely used by pavement engineers due to the desirable simulation of traffic load. In this experiment, a loading plate with a radius of $30 \mathrm{~cm}$ and 7 to 9 sensors installed at different distances from the center of the loading plate is placed on the pavement surface. The FWD applies a type of impulsive load to the pavement surface. To do so, a weight is dropped from a certain height on the loading plate [16].

After the load is applied to the pavement surface, it generates vertical deflections, which are recorded by the sensors. In this study, the resulting deflections are recorded by one geophone below the loading plate and six other geophones that are 20,40,60,90, 120 and $150 \mathrm{~cm}$ away from the center of the loading plate. Deflections are transmitted to the central computer for later applications. Useful information such as remaining service life of the pavement, overlay thickness and layers module can be obtained from the pavement surface deflections [16].

\subsection{Case Study}

In this paper, 236 pavement segments were adopted from the Tehran-Qom freeway in Iran to implement the proposed theory. The understudy route is part of the artery between the capital and southern Iran, which is located in two provinces of Tehran and Qom. The freeway consists of 3 lanes in each direction with a width of $3.65 \mathrm{~m}$ for any lane. This freeway has a flexible pavement. A total of 236 pavement segments were selected from this freeway and the PCI was calculated as described in the subsection: pavement condition index. After calculating PCI, a load was applied to the pavement using an FWD equipped with 7 pavement deflection recording sensors. These sensors recorded the mean deflection in all pavement segments. 


\subsection{Analysis Methods}

Neural networks can be used to explore complex relationships between inputs and outputs of a system. The most common artificial neural networks are MLP and RBF, which have been used in this paper.

\subsubsection{Multi-Layer Perceptron (MLP) Neural Network}

There are three types of layers in MLP. The first layer is the input layer, which is concerned with the input data. The second type of layer is the output layer that deals with the model output. Between the input and output layers, there are intermediate layers known as hidden layers. The number of neurons in the input layer is equal to the number of input variables, while the output is generally the parameter considered for the analysis. The number of hidden layers and neurons in each hidden layer is determined experimentally. Generally, a hidden layer is sufficient for most analyses, but in highly complex systems, two hidden layers could be used. Each neuron in the hidden layer is connected to all the neurons in its preceding and succeeding layers [74]. The amount of each neuron in the hidden layer and the output layer is determined based on the amount of each neuron in the previous layer, weights and bias. To do so, the amount of each neuron in the previous layer is multiplied by its weight and then the sum of the weighted values of neurons in the previous layer is obtained and combined with the bias. The obtained value is passed through an activation function and transferred to the next layer [74]. Various activation functions are used in MLP, including Tansig, Linear, Sigmoid and Tanh.

Optimization algorithms used for model training play a key role in MLP performance. In other words, training optimization in a neural network is equivalent to minimizing a general error function, which is a multivariate function and depends on the weights of the network. In this study, LM and SCG algorithms have been used to optimize MLP.

The LM algorithm introduced by Kenneth Levenberg and Donald Marquardt is a simple and stable convergence algorithm, which represents the most prevalent way of optimizing weights and biases in MLP networks [75]. This algorithm is a combination of the steepest descent method and the Gauss-Newton algorithm, which is designed to alleviate computations by excluding the Hessian matrix [76]. Interested readers can refer to Reference [77] for further details regarding the application of the LM algorithm.

Another set of training algorithms for MLP neural networks is the conjugate gradient (CG) algorithms, for which a variety of algorithms have been presented so far. In conventional CG algorithms, the step size is estimated using the line search technique, which escalates the computational complexity. The SCG algorithm used in this paper is a CG algorithm that eliminates the line search technique and utilizes a step size scaling mechanism, thus accelerating the network learning process $[78,79]$.

The MLP neural network used in this article has 40 neurons in 4 hidden layers for the LM and SCG algorithm. Tansig, Sigmoid, Tansig and Tansig activation functions respectively, were used in hidden layers.

\subsubsection{Radial Basis Function (RBF) Neural Network}

RBF is one of the most popular neural networks, introduced by Broomhead and Lowe in 1988. Employed for both classification and regression purposes, this neural network is inspired by approximation function theory. The RBF generally has a three-layer feed-forward architecture in which an input layer connects to the output layer via a hidden layer [80,81]. Figure 1 illustrates the structure of the RBF neural network adopted in this paper. 


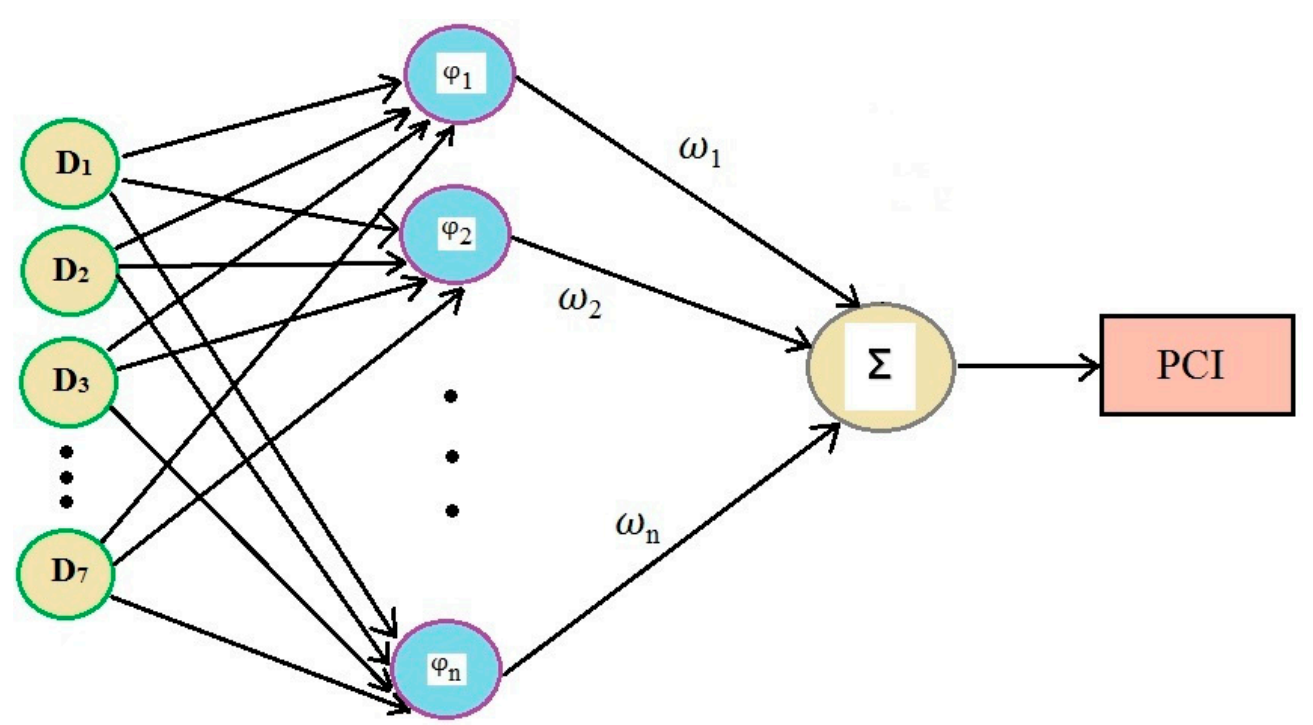

Figure 1. Structure of the radial basis function (RBF) neural network used in this paper.

The input layer contains seven nodes (input variables including $\mathrm{D}_{1}, \mathrm{D}_{2}, \mathrm{D}_{3}, \mathrm{D}_{4}, \mathrm{D}_{5}, \mathrm{D}_{6}$ and $\mathrm{D}_{7}$ ). The main member of the RBF network is the hidden layer that transfers information from the input layer to the hidden space. Each point in the hidden layer is the center of a specific space with a known radius [82]. For inputs of research $\left(\mathrm{D}_{\mathrm{i}}\right)$, the RBF network calculates PCI as Equation (6) [83]:

$$
\mathrm{PCI}=\sum_{\mathrm{j}=1}^{\mathrm{n}} \mathrm{w}_{\mathrm{j}} \varphi_{\mathrm{j}}\left(\left\|\mathrm{D}_{\mathrm{i}}-\mathrm{c}_{\mathrm{j}}\right\|\right)
$$

where, $\mathrm{w}_{\mathrm{j}}$ : connection weight, $\varphi_{\mathrm{j}}$ : radial basis function and $\left\|\mathrm{D}_{\mathrm{i}}-\mathrm{c}_{\mathrm{j}}\right\|$ : Euclidian distance between input data and radial function center.

The radial basis function is commonly taken to be Gaussian, as in Equation (7) [84]:

$$
\varphi_{\mathrm{j}}\left(\left\|\mathrm{D}_{\mathrm{i}}-\mathrm{c}_{\mathrm{j}}\right\|\right)=\exp \left[-\beta\left\|\mathrm{x}-\mathrm{c}_{\mathrm{j}}\right\|^{2}\right]
$$

The Gaussian basis functions is in the center vector in the sense that:

$$
\lim _{\|x\| \rightarrow \infty} \varphi_{j}\left(\left\|D_{i}-c_{j}\right\|\right)=0
$$

Changing parameters of one neuron has only a small effect for input values that are far away from the center of that neuron. The parameters $c_{j}$ and $\beta$ are determined in a manner that optimizes the fit between PCI and the data.

In this paper, GA and ICA algorithms are used to optimize the RBF neural network. GA is a meta-heuristic algorithm inspired by natural selection processes and used for search and optimization problems. In this algorithm, a set of possible solutions, phenotype, is developed for an optimization problem to find better solutions. Each person has a set of chromosomes and genotypes that could be modified or stimulated. In this algorithm, a population of individuals generated in a random process begins to evolve. The fitness (target function value) of each individual in the population is determined and the fittest individuals are selected to produce the next generation. The new generation will be used in the next iteration of the algorithm. This process is sustained until the maximum number of iterations (or the highest number of generations) or the desired accuracy in the optimization problem is achieved $[85,86]$. Figure 2 shows the GA method. 


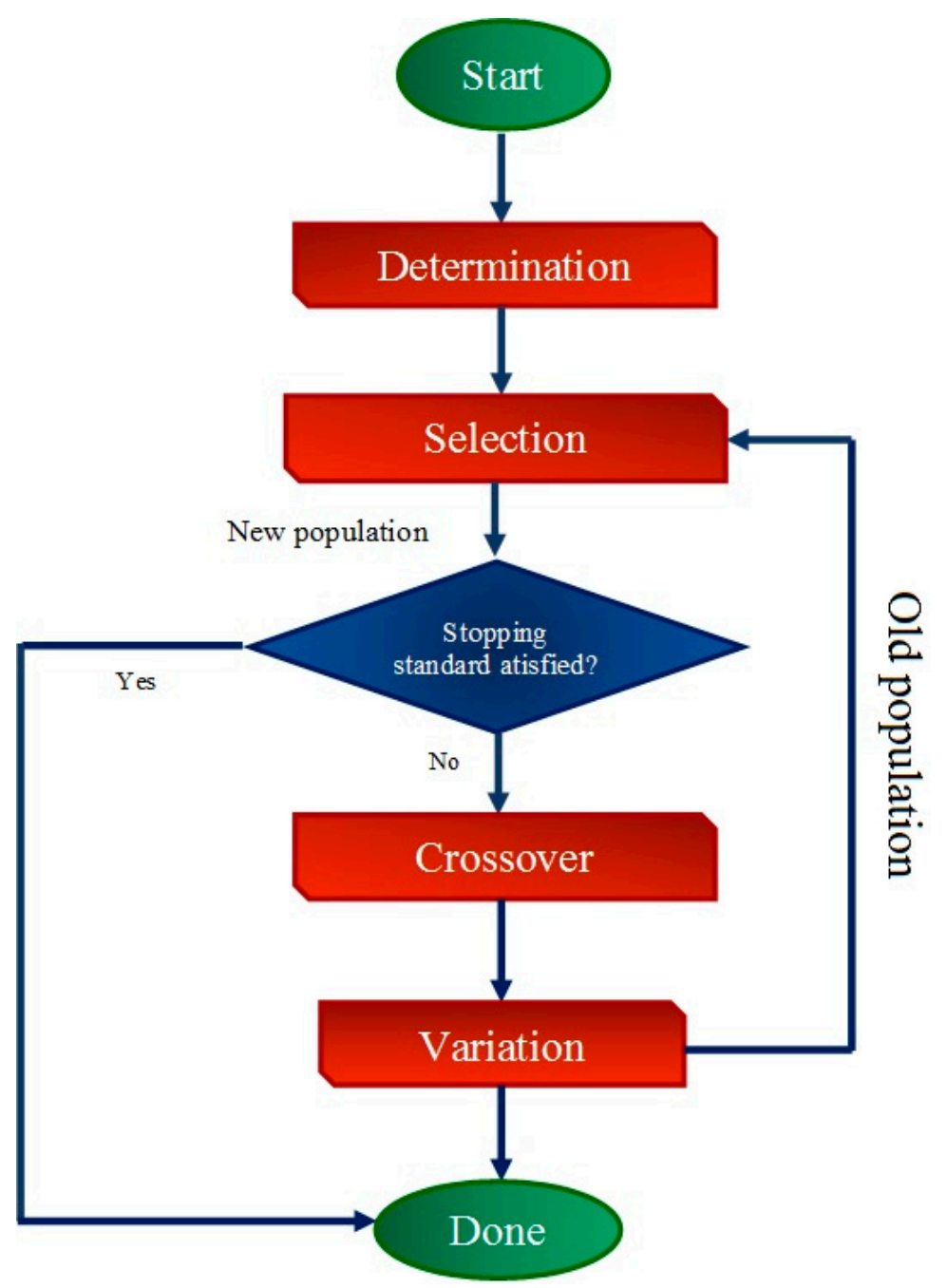

Figure 2. A schematic of the genetic algorithms (GA) method in this study.

ICA is an algorithm inspired by colonial rivalry, representing an evolutionary algorithm for optimization problems. This algorithm was first proposed by Atashpaz-Gargari and Lucas [87]. Like other evolutionary algorithms, ICA begins with an initial population (countries of the world). These countries are split into two categories, including imperialist states and colonies. All colonies are divided among the imperialists incommensurate with their power and dominance. Each empire consists of an imperialist and a few colonies. The power of each empire corresponds to the fitness value at the GA and embraces the power of the colonial state and its colonies [87]. Over time, the colonies begin to launch a movement against the imperialists, and some powerful colonies may be able to seize the power of the empire. In the next stage, a rivalry breaks out between the imperialists, with the strong empires gradually growing in strength and the feeble empires collapsing. The movement of colonies against the imperialists, the rivalry of imperialists and the dissolution mechanism continue until all countries merge into one state with only a single empire while other countries serve as its colonies. Under these conditions, since all colonies are in a relatively identical state and they all have the same position and value, the algorithm ends [87-91]. Figure 3 shows the flowchart of the ICA algorithm adopted from Reference [92]. 


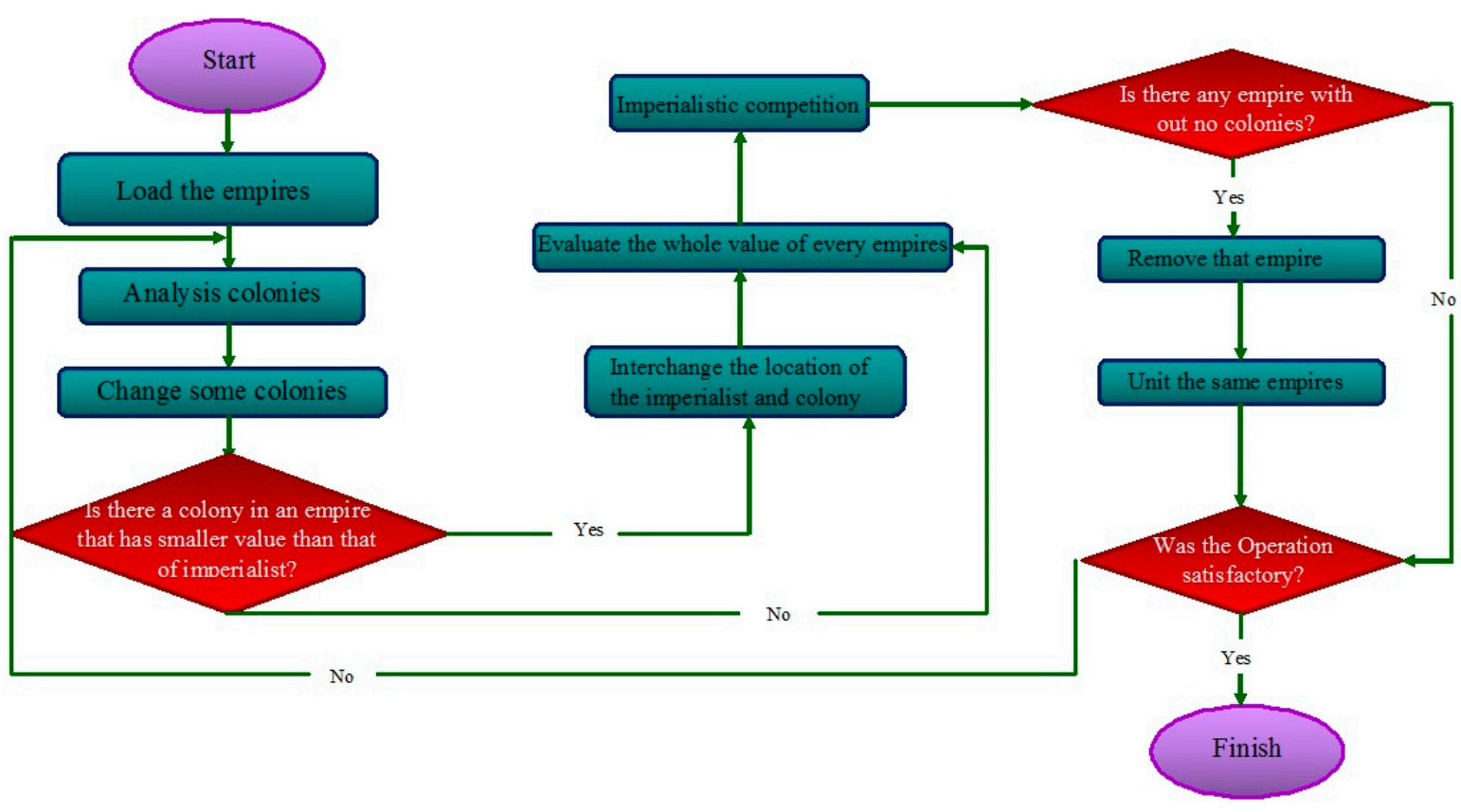

Figure 3. Flowchart of the imperialist competitive algorithm (ICA).

For GA and ICA used in this study, the number of neurons and the distribution coefficient were 55 and 0.37 , respectively.

\subsubsection{Committee Machine Intelligent System (CMIS)}

The standard procedure in intelligence analysis is to consider several models for analysis and then select the best model based on the results. In this process, efforts made for the abandoned models are virtually in vain. This drawback could be fixed by a committee machine. In a committee machine, the results of different models are combined to reach a more accurate answer. The important thing in a committee machine is how to integrate models. In simple arithmetic averaging, all solutions have the same contribution, but in weighted averaging, the solutions are weighted based on their accuracy and then incorporated into the final solution [89-91]. In this paper, the CMIS model was presented by using MLP-LM, MLP-SCG, RBF-GA and RBF-ICA neural networks. Weighted coefficients were optimized by Solver. Table 5 shows the final weighted coefficients in CMIS.

Table 5. Coefficients of committee machine intelligent system (CMIS).

\begin{tabular}{cc}
\hline No. of Coefficients & Coefficients \\
\hline$C_{1}$ & 0 \\
$C_{2}$ & 0.657295 \\
$C_{3}$ & 0.227583 \\
$C_{4}$ & 0.069749 \\
$C_{5}$ & 0.04656 \\
\hline
\end{tabular}

\subsection{Performance Criteria}

In any scientific study, after analyzing data and calculating the analysis output, the results need to be reviewed and verified. Four statistical criteria have been used to validate the results in this study including APRE, AAPRE, RMSE and SD. These criteria are calculated according to the following Equations (9)-(12) [92,93]: 


$$
\begin{aligned}
& \mathrm{APRE}=\frac{100}{\mathrm{~N}} \sum_{\mathrm{i}=1}^{\mathrm{N}} \frac{\mathrm{PCI}_{\text {observed }, \mathrm{i}}-\mathrm{PCI}_{\text {predicted }, \mathrm{i}}}{\mathrm{PCI}_{\text {observed }, \mathrm{i}}} \\
& \text { AAPRE }=\frac{100}{\mathrm{~N}} \sum_{\mathrm{i}=1}^{\mathrm{N}} \frac{\mid \mathrm{PCI}_{\text {observed }_{\mathrm{i}}-\mathrm{PCI}_{\text {predicted }, \mathrm{i}} \mid}}{\mathrm{PCI}_{\text {observed }, \mathrm{i}}} \\
& \text { RMSE }=\sqrt{\frac{1}{N} \sum_{\mathrm{i}=1}^{\mathrm{N}}\left(\mathrm{PCI}_{\text {observed,i }}-\mathrm{PCI}_{\text {predicted }, \mathrm{i}}\right)^{2}}
\end{aligned}
$$

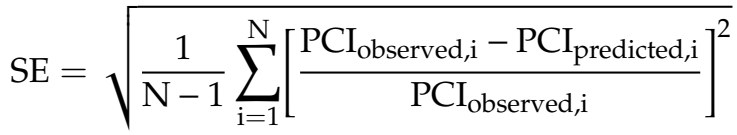

All the above four statistical criteria represent some kind of computational errors, with smaller values close to zero indicating higher accuracy of the modeling results. By examining Equations (9)-(12), it becomes clear that APRE can be negative and the other three criteria are always positive.

\section{Results and Discussion}

This section presents and discusses the achieved results. As mentioned in the previous section, five methods MLP-LM, MLP-SCG, RBF-GA, RBF-ICA and CMIS were applied to the PCI prediction. The modeling input in this study is the pavement surface deflection, which is collected by FWD. Figure 4 shows the relative impact of recorded deflections on PCI. In this figure, $D_{1}$ to $D_{7}$ represents the deflections in geophones 1 to 7, respectively. As shown in Figure 4, geophones 1 to 3 are inversely related while other geophones are directly related to PCI. The deflections in geophone 7 , which is the furthest from the loading spot, yield the highest impact on PCI.

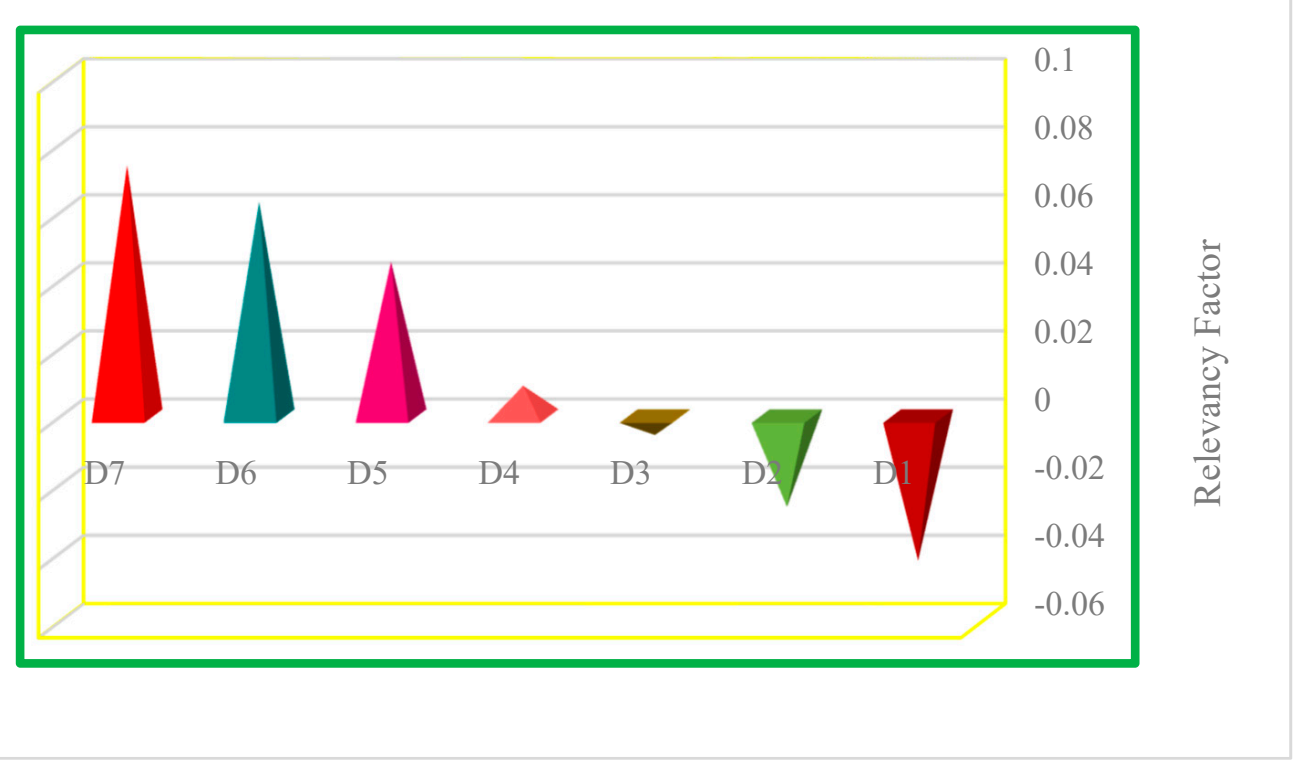

Figure 4. The relative effect of input parameters on PCI. 
Table 6 lists the statistical parameters of APRE, AAPRE, RMSE and SE for all the models developed in this paper. Considering AARPE and APRE values for the CMIS model $(11.67 \%$ and $2.33 \%$, respectively) and lower RMSE and SE errors in the CMIS method compared to other models, this model yields the highest accuracy for predicting PCI among the developed models.

Table 6. Performance criteria of the all developed models for prediction of PCI.

\begin{tabular}{cccccc}
\hline Model & Data & APRE (\%) & AAPRE (\%) & RMSE & SE \\
\hline \multirow{3}{*}{ CMIS } & Train & 3.5636 & 11.6098 & 12.0543 & 0.020082 \\
& Test & -2.632 & 11.9464 & 11.807884 & 0.025687 \\
& Total & 2.3303 & 11.6768 & 12.005653 & 0.021081 \\
& Train & -1.2093 & 14.9275 & 14.541231 & 0.078995 \\
MLP-LM & Test & 4.7599 & 12.7179 & 14.330003 & 0.027158 \\
& Total & -0.02115 & 14.4877 & 14.499431 & 0.068174 \\
& Train & -0.1949 & 15.5046 & 14.167214 & 0.070149 \\
MLP-SCG & Test & 6.6833 & 13.5662 & 15.145498 & 0.031747 \\
& Total & 1.1742 & 15.1187 & 14.367255 & 0.062318 \\
& Train & -0.4446 & 11.8509 & 13.003455 & 0.032987 \\
RBF-GA & Test & 14.2997 & 19.406 & 58.919147 & 0.360989 \\
& Total & 2.4902 & 13.3547 & 28.747779 & 0.096868 \\
& Train & -0.5063 & 12.6392 & 17.077364 & 0.057202 \\
RBF-ICA & Test & 16.7628 & 25.886 & 45.214386 & 0.45286 \\
& Total & 2.9311 & 15.276 & 25.308415 & 0.134177 \\
\hline
\end{tabular}

According to Figure 5, one can visually analyze the quality of all models developed to predict PCI of asphalt pavement. In this figure, a graph is presented for all five models proposed in this research. In each graph, the horizontal axis represents $\mathrm{PCI}_{\text {observed }}$ values and the vertical axis represents $\mathrm{PCI}_{\text {predicted }}$ values. In Figure 5, the higher the data concentration around the $\mathrm{Y}=\mathrm{X}$ line, the higher the accuracy of the model in predicting PCI. As can be seen in this figure, the concentration of points around the $\mathrm{Y}=\mathrm{X}$ line for the CMIS model is higher than other models, so this model has greater precision in predicting $\mathrm{PCI}$.

(a) MLP-LM

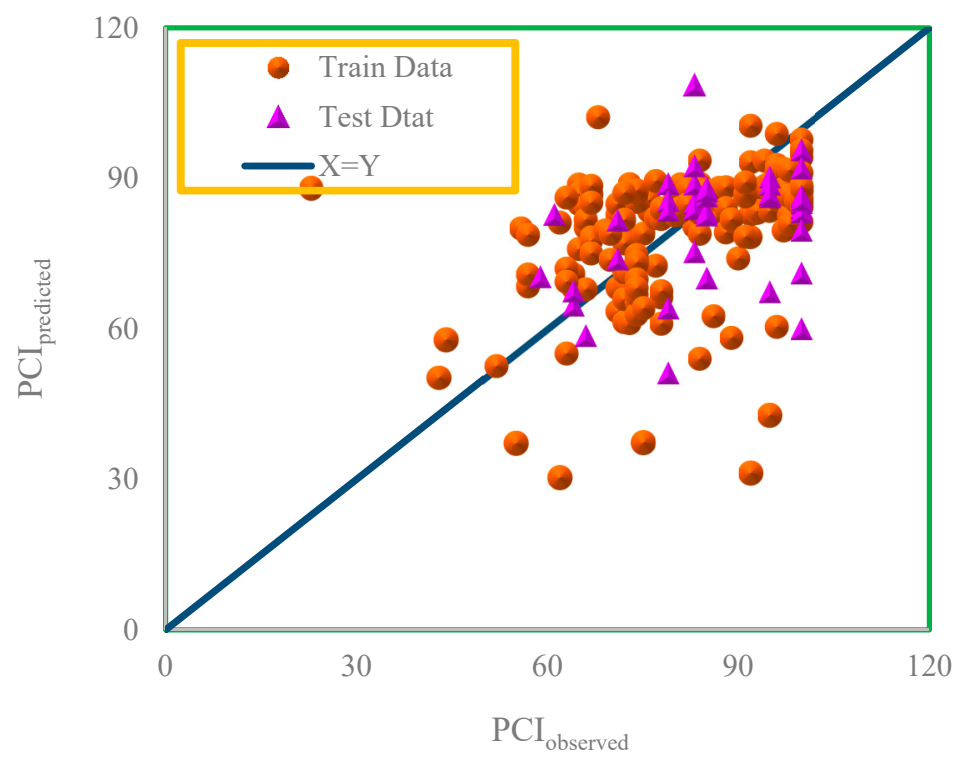

Figure 5. Cont. 
(b) MLP-SCG

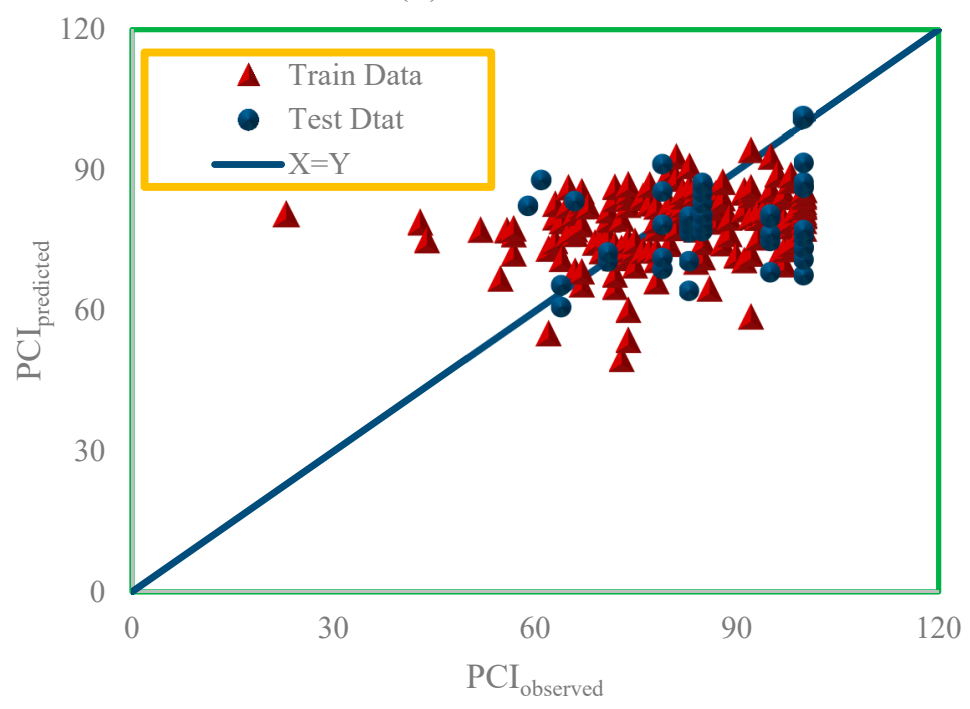

(c) RBF-ICA

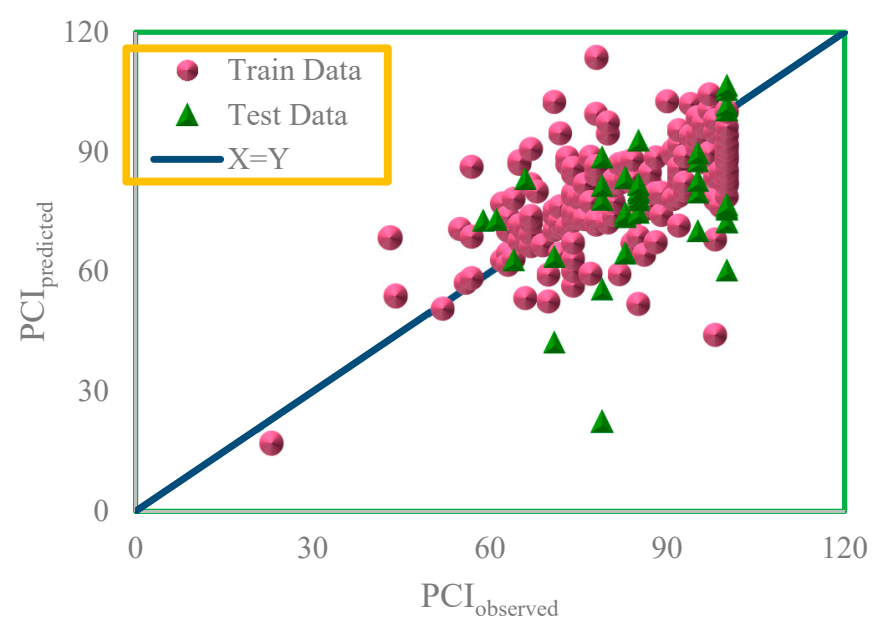

(d) RBF-GA

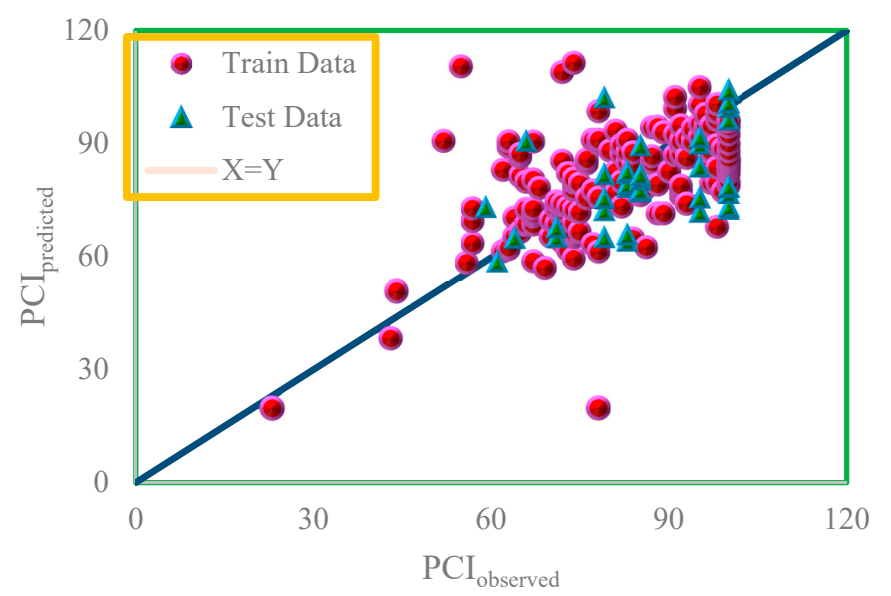

Figure 5. Cont. 


\section{(e) CMIS}

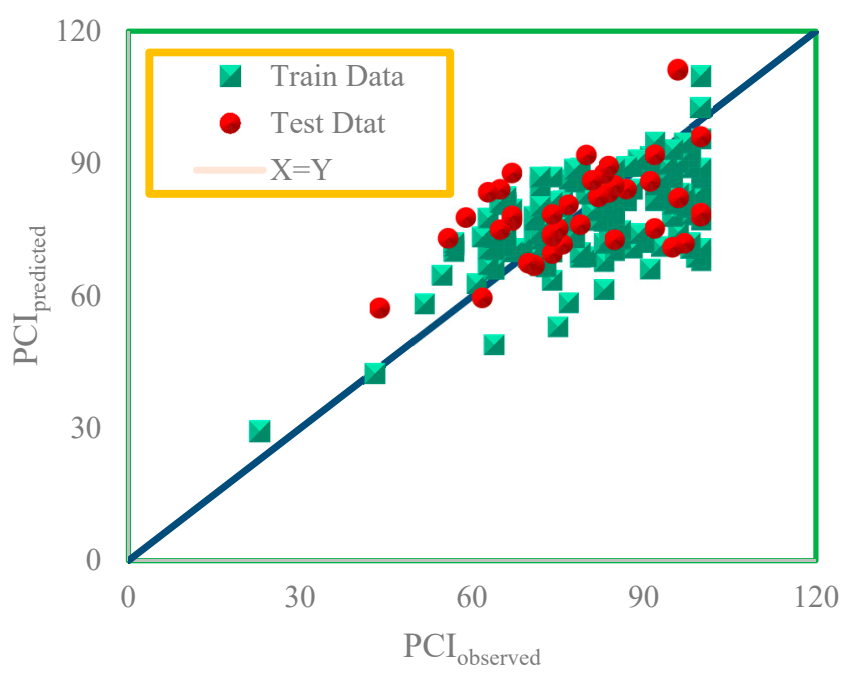

Figure 5. (a) MLP-LM, (b) MLP-SCG, (c) RBF-ICA, (d) RBF-GA, (e) CMIS: cross-plot for developed models for prediction of PCI.

Figure 6 reveals the relative error distribution curves. In general, and for each model, the closer the data points are to the horizontal line of zero error, the greater the accuracy of the model is. According to Figure 6, the highest relative error between $\mathrm{PCI}_{\text {observed }}$ and $\mathrm{PCI}_{\text {predicted }}$ in the CMIS model is less than $33 \%$, which is superior to other models. Thus, Figure 6 also confirms the greater accuracy of the CMIS model compared to other models.

The cumulative frequency curve of AAPRE for models developed in this paper is presented in Figure 7. The analysis of curves in this figure depicts that the quality of results in models based on the RBF neural network is higher than models based on the MLP neural network, especially the RBF-GA model, which has a lower error in PCI prediction. The curve of the CMIS model, which is the median of the results achieved from the four methods: MLP-LM, MLP-SCG, RBF-GA and RBG-ICA, lies in the middle of these four methods. However, the endpoint of the CMIS curve is in a better position than all four methods, which corroborates the higher quality of the CMIS model in PCI prediction.

The results of this section confirm that the proposed method can assist in the intelligent inspection of the roads. To increase model efficiency, it needs to be addressed in future research for it to be applied practically. Future research can improve the modeling accuracy by strengthening the dataset (more pavement segments with various weather and traffic characteristics), using new effective parameters and possibly utilizing new analytical methods.

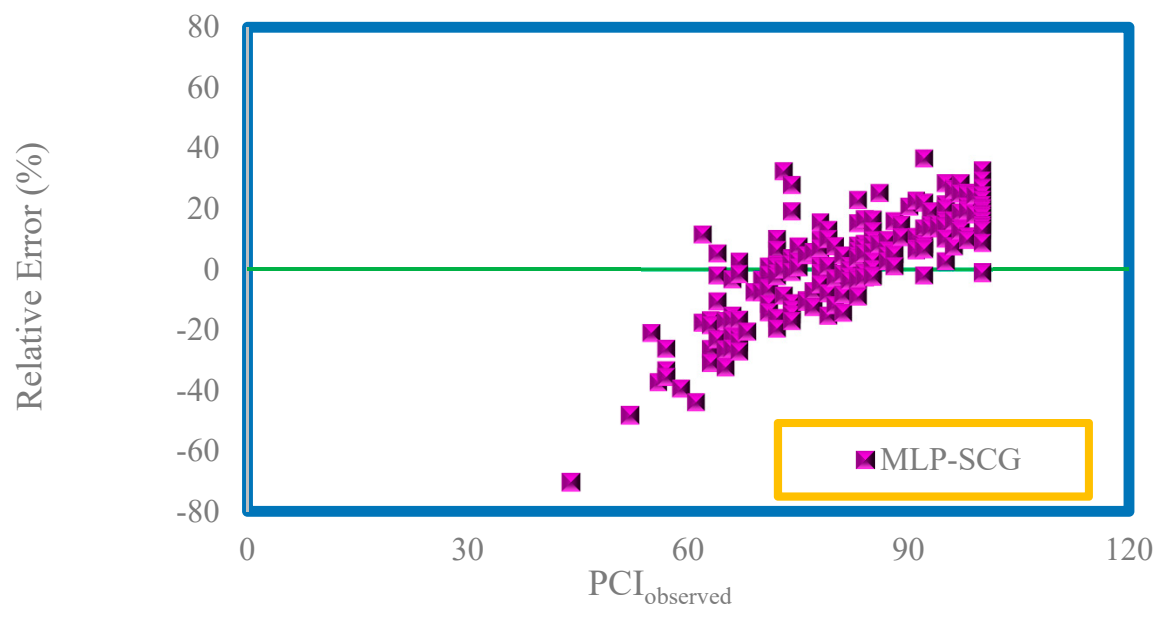

Figure 6. Cont. 

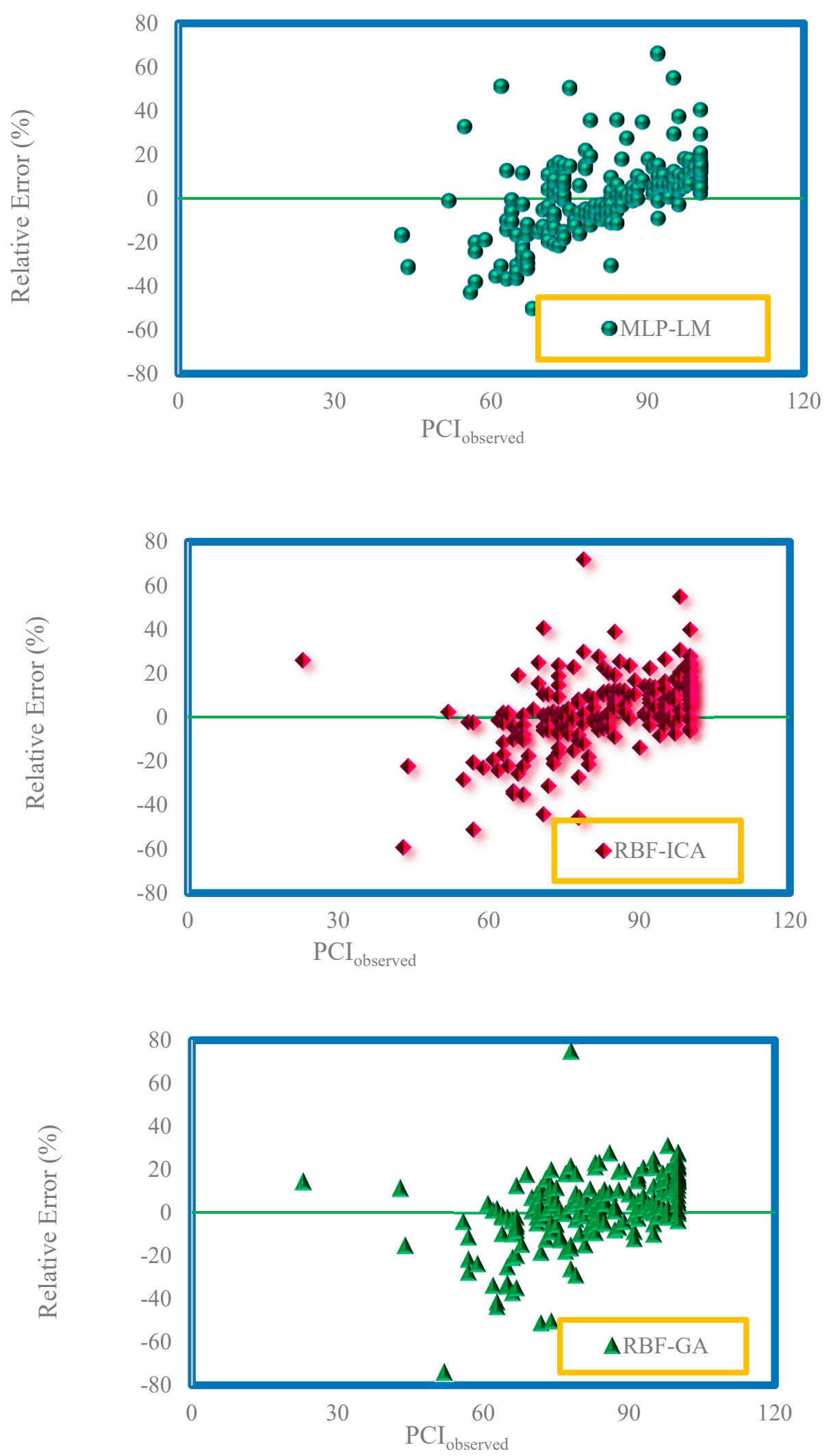

Figure 6. Cont. 


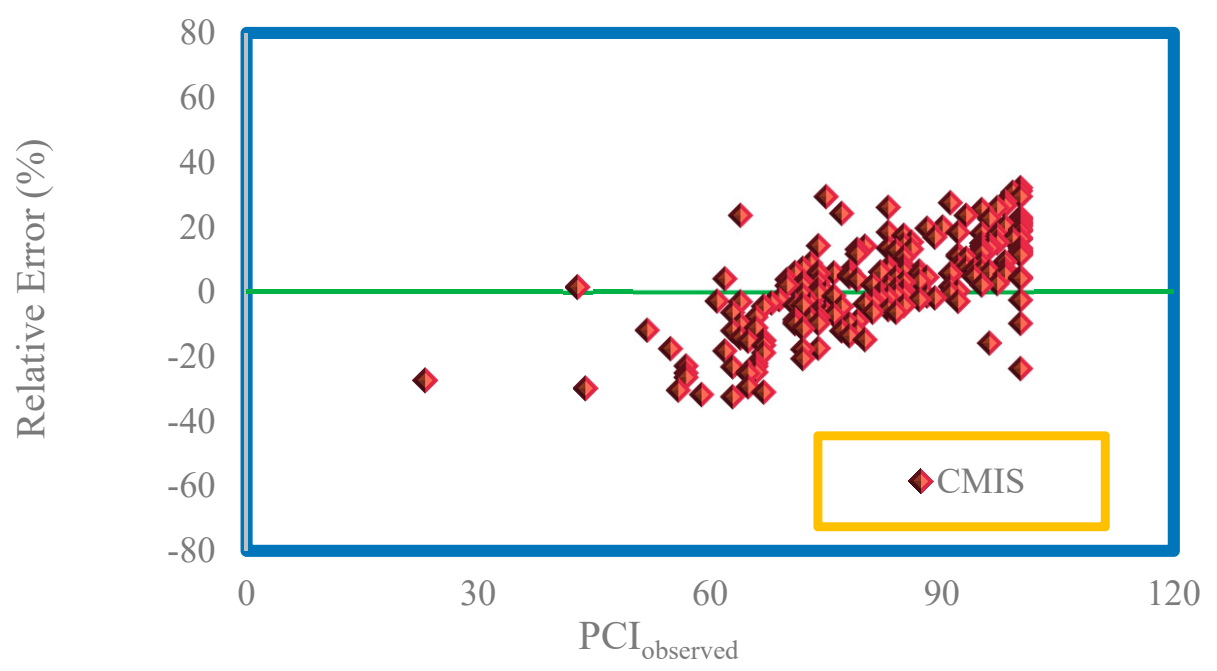

Figure 6. Relative error between the observed and predicted PCI versus observed PCI.

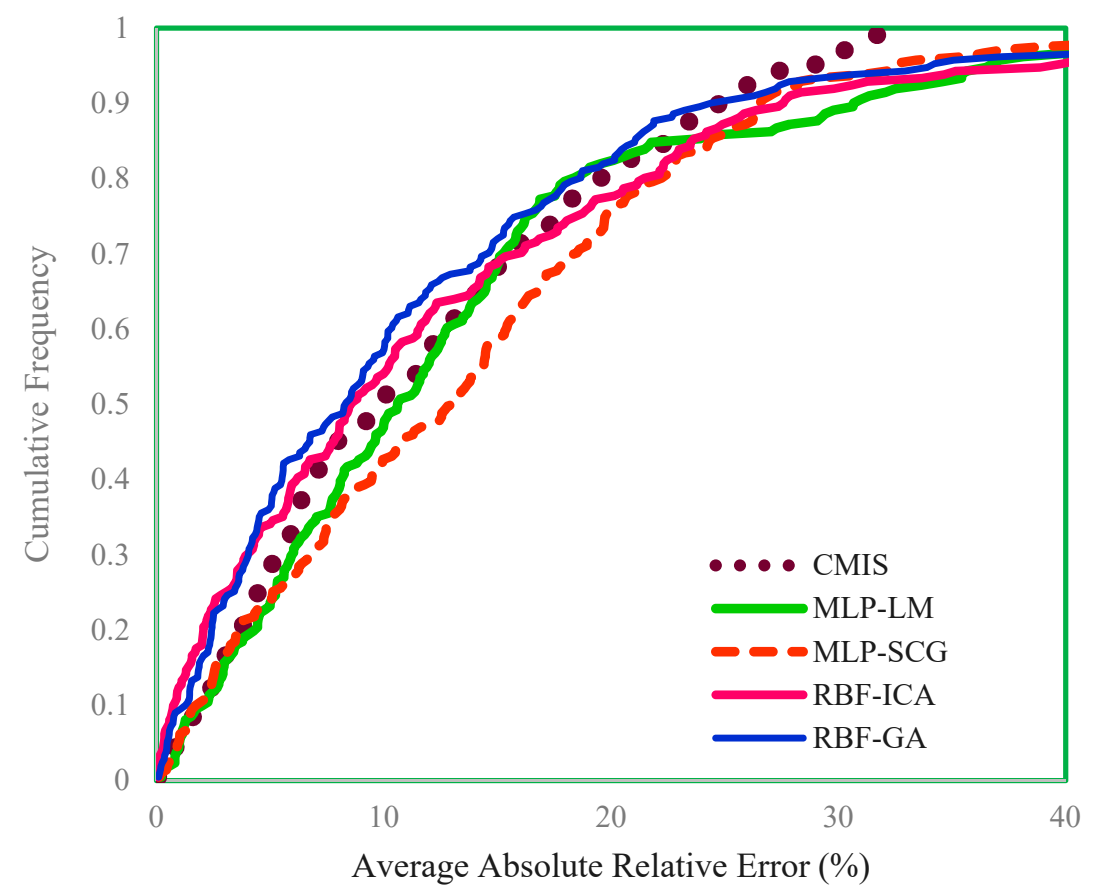

Figure 7. Cumulative frequency curve of average absolute relative error for the developed models in this study to predict PCI.

\section{Conclusions}

In this paper, the authors proposed a new intelligent and automated method for inspection of flexible pavements in highways. They focused on a non-structural index (PCI). They presented a method for estimation of the PCI based on pavement surface deflections. To implement the proposed theory in this paper, a dataset including PCI and pavement surface deflections was collected based on FWD testing of 236 pavement segments taken from Tehran-Qom freeway in Iran. The dataset was analyzed by two MLP and RBF neural networks. LM and SCG algorithms for optimization of the MLP neural network and ICA and GA algorithms for optimization of the RBF neural network were used. To improve the results of the four neural networks adopted in this study, the CMIS method was employed. The results of this paper were verified by four statistical criteria, including APRE, AAPRE, RMSE and SE. For the CMIS method, the values of these criteria were 2.3303, 11.6768, 12.0056 and 0.0210 , respectively. 
Due to financial constraints, most transportation departments and academic centers in many parts of the world, especially Iran, have not yet been equipped with the new pavement inspection devices, such as 2D/3D laser scanning and image-based approaches. Therefore, pavement inspection for pavement management plans is still performed by manual and visual inspection methods. One of the most important indices in pavement management plans is PCI. The proposed method in this paper helps pavement engineers to use the results of the non-destructive test (FWD) for determining PCI rather than a visual and manual survey by the inspector. Therefore, the challenges of the traditional procedure for PCI calculation (dangerous, tedious, variability, labor-intensive, time-consuming, very costly and potential human error) are eliminated. On the other hand, since FWD is generally used in pavement network maintenance programs, the method proposed provides overlapping in pavement maintenance activities and thus saves time and expenses. Of course, to check the economics of the method, pavement engineers can conduct a cost-benefit analysis.

For future research, the authors suggest that modeling becomes more complete. For instance, the results of other non-destructive tests such as GPR are also used. Also, other effective parameters such as traffic volume and weather conditions can be added to the modeling process. Adding new data from pavement segments with different properties can both optimize the model and make the model more comprehensive. On the other hand, after approval in the study phase, new deflectometers (such as RWD and TSD) can be used for recording the pavement surface deflections. Because of having the speed of traffic, these types of equipment have less interference in traffic flow and need less time for gathering surface deflections. It should be kept in mind that with the development of ML techniques, new methods can be employed. The use of these new methods can improve modeling.

Author Contributions: Conceptualization, S.S., A.M. and P.C.; Data curation, N.K. and F.Z.; Formal analysis, N.K., F.Z., N.N. and A.R.V.-K.; Funding acquisition, A.M. and A.R.V.-K.; Investigation, N.K., F.Z. and P.C.; Methodology, S.S. and A.M.; Project administration, A.R.V.-K.; Resources, S.S., N.N., P.C. and A.R.V.-K.; Software, N.K., F.Z., S.S. and N.N.; Supervision, P.C. and A.R.V.-K.; Validation, A.M., N.N. and P.C.; Visualization, N.N.; Writing-original draft, F.Z. and A.M. All authors have read and agreed to the published version of the manuscript.

Funding: This research is supported within the project of "Support of research and development activities of the J. Selye University in the field of Digital Slovakia and creative industry" of the Research and Innovation Operational Programme (ITMS code: NFP313010T504) co-funded by the European Regional Development Fund.

Acknowledgments: We acknowledge the support of this paper within the project of "Support of research and development activities of the J. Selye University in the field of Digital Slovakia and creative industry" of the Research and Innovation Operational Programme (ITMS code: NFP313010T504) co-funded by the European Regional Development Fund. We also acknowledge the support of the German Research Foundation (DFG) and the Bauhaus-Universität Weimar within the Open-Access Publishing Programme.

Conflicts of Interest: The authors declare no conflict of interest.

\section{Abbreviations}

$\begin{array}{ll}\text { Abbreviation } & \text { Description } \\ \text { PCI } & \text { Pavement Condition Index } \\ \text { FWD } & \text { Falling Weight Deflectometer } \\ \text { MLP } & \text { Multi-layer perceptron } \\ \text { RBF } & \text { Radial Basis Function } \\ \text { MLP-LM } & \text { Multi-layer perceptron Optimized by Levenberg-Marquardt Algorithm } \\ \text { MLP-SCG } & \text { Multi-layer perceptron Optimized by Scaled Conjugate Gradient Algorithm } \\ \text { RBF-ICA } & \text { Radial Basis Function Optimized by Imperialist Competitive Algorithm } \\ \text { RBF-GA } & \text { Radial Basis Function Optimized by Genetic Algorithm } \\ \text { CMIS } & \text { Committee Machine Intelligent Systems } \\ \text { APRE } & \text { Average Percent Relative Error } \\ \text { AAPRE } & \text { Average Absolute Percent Relative Error } \\ \text { RMSE } & \text { Root Mean Square Error } \\ \text { SE } & \text { Standard Error }\end{array}$




$\begin{array}{ll}\text { MR\&R } & \text { Maintenance, Rehabilitation, and Reconstruction } \\ \text { PMS } & \text { Pavement Management System } \\ \text { GPR } & \text { Ground Penetrating Radar } \\ \text { LS } & \text { Laser System } \\ \text { ANN } & \text { Artificial Neural Network } \\ \text { SVM } & \text { Support Vector Machine } \\ \text { RF } & \text { Random Forest } \\ \text { DL } & \text { Deep Learning } \\ \text { DM } & \text { Data Mining } \\ \text { GMDH } & \text { Group Method of Data Handling } \\ \text { GEP } & \text { Gene Expression Programming } \\ \text { ANN/SA } & \text { Artificial Neural Network/Simulated Annealing } \\ \text { ML } & \text { Machine Learning } \\ \text { DV } & \text { Deduct Value } \\ \text { TDV } & \text { Total Deduct Value } \\ \text { CDV } & \text { Corrected Deduct Value } \\ \text { CG } & \text { Conjugate Gradient } \\ \text { RWD } & \text { Rolling Weight Deflectometer } \\ \text { TSD } & \text { Traffic Speed Deflectometer }\end{array}$

\section{References}

1. France-Mensah, J.; O’Brien, W.J. Developing a Sustainable Pavement Management Plan: Tradeoffs in Road Condition, User Costs, and Greenhouse Gas Emissions. J. Manag. Eng. 2019, 35, 4019005. [CrossRef]

2. Suraji, A.; Sudjianto, A.T.; Riman, R. Analysis of Road Surface Defects Using Road Condition Index Method on the Caruban-Ngawi Road Segment. J. Sci. Appl. Eng. 2018, 1, 1. [CrossRef]

3. Elbagalati, O.; Elseifi, M.A.; Gaspard, K.; Zhang, Z. Prediction of In-Service Pavement Structural Capacity Based on Traffic-Speed Deflection Measurements. J. Transp. Eng. 2016, 142, 4016058. [CrossRef]

4. Shrestha, S.; Katicha, S.W.; Flintsch, G.W. Pavement Condition Data from Traffic Speed Deflectometer for Network Level Pavement Management. In Airfield and Highway Pavements 2019; American Society of Civil Engineers (ASCE): Reston, VA, USA, 2019; pp. 392-403.

5. Mack, J.W.; Sullivan, R.L. Using remaining service life as the national performance measure of pavement assets 2. In Proceedings of the Annual Meeting of the Transportation Research Board, Washington, DC, USA, 13-17 January 2013; p. 32.

6. Kuo, C.-M.; Tsai, T.-Y. Significance of subgrade damping on structural evaluation of pavements. Road Mater. Pavement Des. 2014, 15, 455-464. [CrossRef]

7. Bryce, J.; Flintsch, G.; Katicha, S.; Diefenderfer, B. Enhancing Network-Level Decision Making through the use of a Structural Capacity Index. Transp. Res. Rec. J. Transp. Res. Board 2013, 2366, 64-70. [CrossRef]

8. Loprencipe, G.; Pantuso, A.; Di Mascio, P. Sustainable Pavement Management System in Urban Areas Considering the Vehicle Operating Costs. Sustainability 2017, 9, 453. [CrossRef]

9. Shah, Y.U.; Jain, S.; Tiwari, D.; Jain, M. Development of Overall Pavement Condition Index for Urban Road Network. Procedia Soc. Behav. Sci. 2013, 104, 332-341. [CrossRef]

10. Kumlai, A.; Sangpetngam, B.; Chalempong, S. Development of equations for determining layer elastic moduli using pavement deflection characteristics. TRB Pap. 2013, 92, 14-0976.

11. Long, B.; Shatnawi, S. Structural evaluation of rigid pavement sections. Road Mater. Pavement Des. 2000, 1, 97-117. [CrossRef]

12. García, J.A.R.; Castro, M. Analysis of the temperature influence on flexible pavement deflection. Constr. Build. Mater. 2011, 25, 3530-3539. [CrossRef]

13. Djaha, S.I.K.; Prayuda, H. Quality Assessment of Road Pavement using Lightweight Deflectometer. In Proceedings of the Third International Conference on Sustainable Innovation 2019-Technology and Engineering (IcoSITE 2019), Yogyakarta, Indonesia, 30-31 July 2019; Atlantis Press: Paris, France, 2019.

14. Ullidtz, P. Pavement Analysis. Developments in Civil Engineering; North Holland: Amsterdam, The Netherlands, 1987.

15. Kutay, M.E.; Chatti, K.; Lei, L. Backcalculation of Dynamic Modulus Mastercurve from Falling Weight Deflectometer Surface Deflections. Transp. Res. Rec. J. Transp. Res. Board 2011, 2227, 87-96. [CrossRef] 
16. Karballaeezadeh, N.; Mohammadzadeh, S.D.; Shamshirband, S.; Hajikhodaverdikhan, P.; Mosavi, A.; Chau, K.-W. Prediction of remaining service life of pavement using an optimized support vector machine (case study of Semnan-Firuzkuh road). Eng. Appl. Comput. Fluid Mech. 2019, 13, 188-198. [CrossRef]

17. Kargah-Ostadi, N. Comparison of Machine Learning Techniques for Developing Performance Prediction Models. In Computing in Civil and Building Engineering (2014); American Society of Civil Engineers: Reston, VA, USA, 2014; pp. 1222-1229.

18. Chou, J.; O'Neill, W.; Cheng, H. Pavement distress classification using neural networks. In Proceedings of the IEEE International Conference on Systems, Man and Cybernetics, San Antonio, TX, USA, 3-5 October 2002; Volume 1, pp. 397-401.

19. Eldin, N.N.; Senouci, A. Condition rating of rigid pavements by neural networks. Can. J. Civ. Eng. 1995, 22, 861-870. [CrossRef]

20. Owusu-Ababio, S. Application of Neural Networks to Modeling Thick Asphalt Pavement Performance. Artif. Intell. Math. Methods Pavement Geomech. Syst. 1998, 25, 23-30.

21. Sundin, S.; Braban-Ledoux, C. Artificial Intelligence-Based Decision Support Technologies in Pavement Management. Comput. Civ. Infrastruct. Eng. 2001, 16, 143-157. [CrossRef]

22. Yang, J.; Lu, J.J.; Gunaratne, M.; Xiang, Q. Forecasting Overall Pavement Condition with Neural Networks: Application on Florida Highway Network. Transp. Res. Rec. J. Transp. Res. Board 2003, 1853, 3-12. [CrossRef]

23. Gopalakrishnan, K. Neural Network-Swarm Intelligence Hybrid Nonlinear Optimization Algorithm for Pavement Moduli Back-Calculation. J. Transp. Eng. 2010, 136, 528-536. [CrossRef]

24. Terzi, S.; Saltan, M.; Küçüksille, E.U.; Karaşahin, M. Backcalculation of pavement layer thickness using data mining. Neural Comput. Appl. 2012, 23, 1369-1379. [CrossRef]

25. Nejad, F.M.; Motekhases, F.Z.; Zakeri, H.; Wang, L.-J.; Monaghan, J.M. An Image Processing Approach to Asphalt Concrete Feature Extraction. J. Ind. Intell. Inf. 2014, 3, 3. [CrossRef]

26. Ziari, H.; Maghrebi, M.; Ayoubinejad, J.; Waller, T. Prediction of Pavement Performance: Application of Support Vector Regression with Different Kernels. Transp. Res. Rec. J. Transp. Res. Board 2016, 2589, $135-145$. [CrossRef]

27. Georgiou, P.; Plati, C.; Loizos, A. Soft Computing Models to Predict Pavement Roughness: A Comparative Study. Adv. Civ. Eng. 2018, 2018, 1-8. [CrossRef]

28. Fathi, A.; Mazari, M.; Saghafi, M.; Hosseini, A.; Kumar, S. Parametric Study of Pavement Deterioration Using Machine Learning Algorithms. In Airfield and Highway Pavements 2019; American Society of Civil Engineers (ASCE): Reston, VA, USA, 2019; pp. 31-41.

29. Santos, J.; Ferreira, A.; Flintsch, G. An adaptive hybrid genetic algorithm for pavement management. Int. J. Pavement Eng. 2017, 20, 266-286. [CrossRef]

30. Zakeri, H.; Nejad, F.M.; Fahimifar, A. Image Based Techniques for Crack Detection, Classification and Quantification in Asphalt Pavement: A Review. Arch. Comput. Methods Eng. 2016, 24, 935-977. [CrossRef]

31. Cheng, H.; Miyojim, M. Automatic pavement distress detection system. Inf. Sci. 1998, 108, $219-240$. [CrossRef]

32. Huang, J.; Liu, W.; Sun, X. A Pavement Crack Detection Method Combining 2D with 3D Information Based on Dempster-Shafer Theory. Comput. Civ. Infrastruct. Eng. 2013, 29, 299-313. [CrossRef]

33. Inzerillo, L.; Di Mino, G.; Roberts, R. Image-based 3D reconstruction using traditional and UAV datasets for analysis of road pavement distress. Autom. Constr. 2018, 96, 457-469. [CrossRef]

34. Chen, D.; Sefidmazgi, N.R.; Bahia, H. Exploring the feasibility of evaluating asphalt pavement surface macro-texture using image-based texture analysis method. Road Mater. Pavement Des. 2015, 16, 405-420. [CrossRef]

35. Wu, L.; Mokhtari, S.; Nazef, A.; Nam, B.; Yun, H.-B. Improvement of Crack-Detection Accuracy Using a Novel Crack Defragmentation Technique in Image-Based Road Assessment. J. Comput. Civ. Eng. 2016, 30, 04014118. [CrossRef]

36. Han, J.-Y.; Chen, A.; Lin, Y.-T. Image-Based Approach for Road Profile Analyses. J. Surv. Eng. 2016, 142, 06015003. [CrossRef]

37. Solla, M.; Lagüela, S.; González-Jorge, H.; Arias, P. Approach to identify cracking in asphalt pavement using GPR and infrared thermographic methods: Preliminary findings. NDT E Int. 2014, 62, 55-65. [CrossRef]

38. Chapeleau, X.; Blanc, J.; Hornych, P.; Gautier, J.-L.; Carroget, J. Use of distributed fiber optic sensors to detect damage in a pavement. Asph. Pavements 2014, 449-457. 
39. Chang, K.-T.; Chang, J.-R.; Liu, J.-K. Detection of Pavement Distresses Using 3D Laser Scanning Technology. In Computing in Civil Engineering (2005); American Society of Civil Engineers (ASCE): Reston, VA, USA, 2005; pp. 1-11.

40. Bitelli, G.; Simone, A.; Girardi, F.; Lantieri, C. Laser Scanning on Road Pavements: A New Approach for Characterizing Surface Texture. Sensors 2012, 12, 9110-9128. [CrossRef] [PubMed]

41. Tsai, Y.-C.; Li, F. Critical Assessment of Detecting Asphalt Pavement Cracks under Different Lighting and Low Intensity Contrast Conditions Using Emerging 3D Laser Technology. J. Transp. Eng. 2012, 138, 649-656. [CrossRef]

42. Park, K.; Thomas, N.; Lee, K.W. Applicability of the International Roughness Index as a Predictor of Asphalt Pavement Condition1. J. Transp. Eng. 2007, 133, 706-709. [CrossRef]

43. Dewan, S.; Smith, R. Estimating IRI from pavement distresses to calculate vehicle operating costs for the cities and counties of San Francisco Bay area. Transp. Res. Rec. J. Transp. Res. Board 2002, 1816, 65-72. [CrossRef]

44. Arhin, S.A.; Williams, L.N.; Ribbiso, A.; Anderson, M.F. Predicting pavement condition index using international roughness index in a dense urban area. J. Civil. Eng. Res. 2015, 5, 10-17.

45. Suh, Y.-C.; Kwon, H.-J.; Park, K.-S.; Ohm, B.-S.; Kim, B.-I. Correlation Analysis between Pavement Condition Indices in Korean Roads. KSCE J. Civ. Eng. 2017, 22, 1162-1169. [CrossRef]

46. Ningyuan, L.; Kazmierowski, T.; Tighe, S.; Haas, R. Integrating dynamic performance prediction models into pavement management maintenance and rehabilitation programs. In Proceedings of the 5th International Conference on Managing Pavements, Chicago, IL, USA, 11-14 August 2001.

47. Khattak, M.J. Development of Uniform Sections for PMS Inventory and Application-Interim Report; Louisiana Transportation Research Center: Baton Rouge, LA, USA, 2009.

48. Chen, J.-S.; Wangdi, K. Proposal of a New Road Surface Management System(RSMS) for Developing Countries. Doboku Gakkai Ronbunshu 1999, 618, 83-94. [CrossRef]

49. Yuan, J.; Mooney, M.A. Development of Adaptive Performance Models for Oklahoma Airfield Pavement Management System. Transp. Res. Rec. J. Transp. Res. Board 2003, 1853, 44-54. [CrossRef]

50. Michels, D.J. Pavement Condition Index and Cost of Ownership Analysis on Preventative Maintenance Projects in Kentucky. Master's Thesis, University of Kentucky, Lexington, KY, USA, 2017.

51. O'Brien, D.E., III; Kohn, S.D.; Shahin, M.Y. Prediction of Pavement Performance by Using Nondestructive Test Results. Transp. Res. Rec. 1983, 943, 13.

52. Nivedya, M.; Mallick, R.B. Accurate prediction of laboratory permeability of hot mix asphalt using machine learning techniques. In Proceedings of the Advances in Materials and Pavement Performance Prediction, Doha, Qatar, 16-18 April 2018; pp. 133-137.

53. Nivedya, M.K.; Mallick, R.B. A multi-structure multi-run range (MSMRR) approach for using machine learning with constrained data in pavement engineering. SN Appl. Sci. 2020, 2, 1-10. [CrossRef]

54. Inkoom, S.; Sobanjo, J.; Barbu, A.; Niu, X. Prediction of the crack condition of highway pavements using machine learning models. Struct. Infrastruct. Eng. 2019, 15, 940-953. [CrossRef]

55. Lin, J.-D.; Yau, J.-T.; Hsiao, L.-H. Correlation analysis between international roughness index (IRI) and pavement distress by neural network. In Proceedings of the 82nd Annual Meeting of the Transportation Research Board, Washington, DC, USA, 12-16 January 2003; pp. 12-16.

56. Bianchini, A.; Bandini, P. Prediction of Pavement Performance through Neuro-Fuzzy Reasoning. Comput. Civ. Infrastruct. Eng. 2010, 25, 39-54. [CrossRef]

57. Kargah-Ostadi, N.; Stoffels, S.M.; Tabatabaee, N. Network-Level Pavement Roughness Prediction Model for Rehabilitation Recommendations. Transp. Res. Rec. J. Transp. Res. Board 2010, 2155, 124-133. [CrossRef]

58. Kargah-Ostadi, N.; Stoffels, S.M. Framework for Development and Comprehensive Comparison of Empirical Pavement Performance Models. J. Transp. Eng. 2015, 141, 4015012. [CrossRef]

59. Ziari, H.; Sobhani, J.; Ayoubinejad, J.; Hartmann, T. Prediction of IRI in short and long terms for flexible pavements: ANN and GMDH methods. Int. J. Pavement Eng. 2015, 17, 1-13. [CrossRef]

60. Hoang, N.-D.; Nguyen, Q.-L. A novel method for asphalt pavement crack classification based on image processing and machine learning. Eng. Comput. 2018, 35, 487-498. [CrossRef]

61. Mazari, M.; Rodriguez, D.D. Prediction of pavement roughness using a hybrid gene expression programming-neural network technique. J. Traffic Transp. Eng. (English Ed.) 2016, 3, 448-455. [CrossRef] 
62. Nabipour, N.; Karballaeezadeh, N.; Dineva, A.; Mosavi, A.; Mohammadzadeh, S.D.; Shamshirband, S. Comparative Analysis of Machine Learning Models for Prediction of Remaining Service Life of Flexible Pavement. Mathematics 2019, 7, 1198. [CrossRef]

63. Fujita, Y.; Shimada, K.; Ichihara, M.; Hamamoto, Y. A method based on machine learning using hand-crafted features for crack detection from asphalt pavement surface images. In Proceedings of the Thirteenth International Conference on Quality Control by Artificial Vision 2017, Tokyo, Japan, 14-16 May 2017; Volume 10338 , p. 103380.

64. Marcelino, P.; Antunes, M.D.L.; Fortunato, E.; Gomes, M.C. Machine learning approach for pavement performance prediction. Int. J. Pavement Eng. 2019, 1-14. [CrossRef]

65. Zhang, A.; Wang, K.C.P.; Li, B.; Yang, E.; Dai, X.; Peng, Y.; Fei, Y.; Liu, Y.; Li, J.Q.; Chen, C. Automated Pixel-Level Pavement Crack Detection on 3D Asphalt Surfaces Using a Deep-Learning Network. Comput. Civ. Infrastruct. Eng. 2017, 32, 805-819. [CrossRef]

66. Ziari, H.; Sobhani, J.; Ayoubinejad, J.; Hartmann, T. Analysing the accuracy of pavement performance models in the short and long terms: GMDH and ANFIS methods. Road Mater. Pavement Des. 2015, 17, 1-19. [CrossRef]

67. Majidifard, H.; Jahangiri, B.; Buttlar, W.G.; Alavi, A.H. New machine learning-based prediction models for fracture energy of asphalt mixtures. Measurement 2019, 135, 438-451. [CrossRef]

68. Marcelino, P.; Antunes, M.D.L.; Fortunato, E.; Gomes, M.C. Machine Learning for Pavement Friction Prediction Using Scikit-Learn. In Proceedings of the Requirements Engineering: Foundation for Software Quality, Essen, Germany, 27 February-2 March 2017; Volume 10423, pp. 331-342.

69. Shahin, M.Y.; Kohn, S.D. Pavement Maintenance Management for Roads and Parking Lots; Construction Engineering Research Lab (Army): Champaign, IL, USA, 1981.

70. Shahnazari, H.; Tutunchian, M.A.; Mashayekhi, M.; Amini, A.A. Application of Soft Computing for Prediction of Pavement Condition Index. J. Transp. Eng. 2012, 138, 1495-1506. [CrossRef]

71. ASTM D6433-07. Standard Practice for Roads and Parking Lots Pavement Condition Index Surveys; American Society for Testing and Materials: West Conshohocken, PA, USA, 2007.

72. Shahin, M.Y. Pavement Management for Airports, Roads, and Parking Lots; Springer: Berlin/Heidelberg, Germany, 1994; Volume 501.

73. Levenberg, E.; Pettinari, M.; Baltzer, S.; Christensen, B.M.L. Comparing Traffic Speed Deflectometer and Falling Weight Deflectometer Data. Transp. Res. Rec. J. Transp. Res. Board 2018, 2672, 22-31. [CrossRef]

74. Nejad, F.M.; Mehrabi, A.; Zakeri, H. Prediction of Asphalt Mixture Resistance Using Neural Network via Laboratorial X-ray Images. J. Ind. Intell. Inf. 2014, 3, 3. [CrossRef]

75. Yu, H.; Wilamowski, B. Levenberg-Marquardt Training. VLSI Handb. 2011, 5, 1-16.

76. Huang, C.; Chen, F.; Chang, Y.; Han, L.; Li, S.; Hong, J. Adaptive Operator-Based Spectral Deconvolution with the Levenberg-Marquardt Algorithm. Photon. Sens. 2019, 11, 1-12. [CrossRef]

77. Hagan, M.; Menhaj, M. Training feedforward networks with the Marquardt algorithm. IEEE Trans. Neural Netw. 1994, 5, 989-993. [CrossRef]

78. Møller, M.F. A scaled conjugate gradient algorithm for fast supervised learning. Neural Netw. 1993, 6, 525-533. [CrossRef]

79. Kişi, Ö.; Uncuoğlu, E. Comparison of Three Back-Propagation Training Algorithms for Two Case Studies; CSIR: Pretoria, South Africa, 2005.

80. Broomhead, D.S.; Lowe, D. Radial Basis Functions, Multi-Variable Functional Interpolation and Adaptive Networks; Royal Signals and Radar Establishment Malvern: Malvern, UK, 1988.

81. Sheng, Z. Pavement performance evaluating model by using RBF. J. Highw. Transp. Res. Dev. 2008, 3, $23-26$.

82. Yildirim, S.; Uzmay, I. Statistical analysis of vehicles' vibration due to road roughness using radial basis artificial neural network. Appl. Artif. Intell. 2001, 15, 419-427. [CrossRef]

83. Karim, A.; Adeli, H. Radial Basis Function Neural Network for Work Zone Capacity and Queue Estimation. J. Transp. Eng. 2003, 129, 494-503. [CrossRef]

84. Ardabili, S.F.; Mahmoudi, A.; Gundoshmian, T.M. Modeling and simulation controlling system of HVAC using fuzzy and predictive (radial basis function, RBF) controllers. J. Build. Eng. 2016, 6, 301-308. [CrossRef]

85. Davis, L. Handbook of Genetic Algorithms; Van Nostrand Reinhold: New York, NY, USA, 1991.

86. Alam, N.; Das, B.; Pant, V. A comparative study of metaheuristic optimization approaches for directional overcurrent relays coordination. Electr. Power Syst. Res. 2015, 128, 39-52. [CrossRef] 
87. Atashpaz-Gargari, E.; Lucas, C. Imperialist competitive algorithm: An algorithm for optimization inspired by imperialistic competition. In Proceedings of the 2007 IEEE Congress on Evolutionary Computation, Singapore, 25-28 September 2007; pp. 4661-4667.

88. Hosseini, S.; Al Khaled, A. A survey on the Imperialist Competitive Algorithm metaheuristic: Implementation in engineering domain and directions for future research. Appl. Soft Comput. 2014, 24, 1078-1094. [CrossRef]

89. Nilsson, N.J. Learning Machines; American Psychological Association: Washington, DC, USA, 1965.

90. Hashem, S.; Schmeiser, B. Approximating a Function and Its Derivatives Using MSE-Optimal Linear Combinations of Trained Feedforward Neural Networks; Purdue University, Department of Statistics: West Lafayette, IN, USA, 1993.

91. Perrone, M.P.; Cooper, L.N. When networks disagree: Ensemble methods for hybrid neural networks; Brown Univ Providence Ri Inst for Brain and Neural Systems: Providence, RI, USA, 1992.

92. Sarapardeh, A.H.; Varamesh, A.; Husein, M.M.; Karan, K. On the evaluation of the viscosity of nanofluid systems: Modeling and data assessment. Renew. Sustain. Energy Rev. 2018, 81, 313-329. [CrossRef]

93. Ardabili, S.F.; Najafi, B.; Alizamir, M.; Mosavi, A.; Shamshirband, S.; Rabczuk, T. Using SVM-RSM and ELM-RSM Approaches for Optimizing the Production Process of Methyl and Ethyl Esters. Energies 2018, 11, 2889. [CrossRef]

(C) 2020 by the authors. Licensee MDPI, Basel, Switzerland. This article is an open access article distributed under the terms and conditions of the Creative Commons Attribution (CC BY) license (http://creativecommons.org/licenses/by/4.0/). 